\title{
Caminos de resistencia al desarrollo de la explotación en Guatemala
}

Ana Clarice Mendonça Oliveira

RESUMEN: La expansión del modelo de desarrollo neoliberal ha rediseñado prácticas de acumulación por despojo, profundizando la instrumentalización de aparatos estatales en beneficio de sectores extractivistas, con renovados mecanismos discursivos vinculados a prácticas de subordinación y explotación de los pueblos y sus bienes naturales. Frente a ello, en Guatemala, iniciativas de autogestión, combinan prácticas innovadoras y caminos ancestrales de resistencia, remitiéndose a la vida comunitaria y espiritualidad de los pueblos originarios.

PALABRAS ClAVE: Estado.

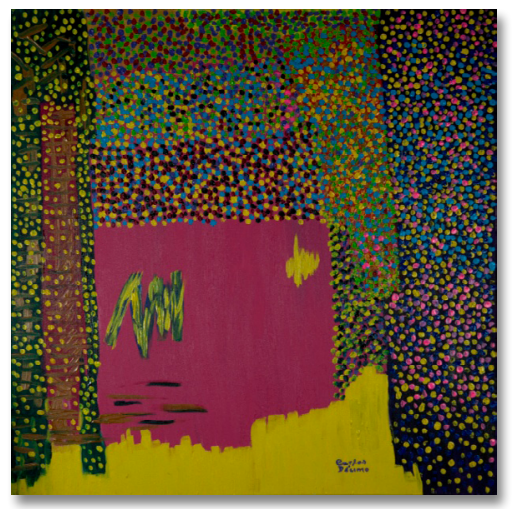

Extractivismo. Inversiones transnacionales. Criminalización. Resistencia.

\section{Paths of resistance against the development of exploitation in Guatemala}

\footnotetext{
Ana Clarice Mendonça Oliveira

Licenciada en Ciencias Sociales por la UFC. Máster en Antropología por la Universidad de Sevilla, España. Máster en Ciencias Sociales por la Universität Albert-Ludwigs, Alemania, y FLACSO, Argentina. Investigadora de O Istmo y del GT El istmo, vinculado al CLACSO. Profesora de la UECE. E-mail: ana.clarice@hotmail.com
}

\begin{abstract}
The expansion of the neoliberal development model has redesigned practices of accumulation by dispossession, deepening the instrumentalization of state apparatuses for the benefit of extractive sectors, with renewed discursive mechanisms linked to practices of subordination and exploitation of peoples and their natural goods. Faced with this, in Guatemala, self-management initiatives combine innovative practices and ancestral paths of resistance, referring to the community life and spirituality of the indigenous peoples.
\end{abstract}

KEYWORDS: State. Extrativism. Transnational Investments. Criminalization. Resistance.

RECEBIDO EM: 08/05/2019

APROVADO EM: $27 / 08 / 2019$ 


\section{Introducción}

Con el progresivo avance de las dinámicas del mercado globalizado, intensificadas a través de las recalcitrantes estructuras de despojo inauguradas con la invasión colonial, las expresiones de la política en América Latina se han visto cargadas por la creciente sofisticación de mecanismos de control territorial y subordinación de los pueblos.

Mi argumento central en este trabajo enfatiza, por lo tanto, que dichos mecanismos solamente se hacen posibles con la activa participación del Estado, que no puede verse como un agente neutro, actuando en la mediación de una disputa entre pares, sino como todo un conjunto de aparatos que son sistemáticamente instrumentalizados en favor de intereses privados, articulados en interacción dialéctica con aquellas y aquellos que osan confrontarse a dichas estructuras, en la construcción de sus caminos de resistencia. De modo que, en la reproducción del antagonismo capital-trabajo, la obstinada búsqueda de acumulación de recursos entra en choque directo con formas de vida marcadas por el rescate de referentes de autonomía y soberanía, extirpadas a lo largo de siglos de violencia colonial.

En ese marco, presento resultados de una estancia de investigación ${ }^{1}$ que realicé en el 2015, en Guatemala, seguida de mi regreso al final del 2017 para el mismo país, con el objetivo de dar seguimiento a conversaciones pendientes con algunos líderes y autoridades ancestrales. Sumado al trabajo etnográfico y a las entrevistas, se dieron otras vías de seguimiento a los hechos políticos en el país, a los que he conocido, sobre todo, a través de medios de comunicación corporativos y alternativos, así como informes oficiales.

Empiezo, entonces, con algunas consideraciones acerca del Estado, tratando de contribuir con el debate que evidencia las falacias de los discursos neoliberales, que, bajo la premisa de la defensa de su sentido de la libertad, vinculada a un modelo de

1 Investigación realizada con el apoyo del DAAD de Alemania, durante mi maestría en Estudios de la Globalización por la Universität Albert-Ludwigs, en Alemania, y FLACSO, en Argentina. 
desarrollo basado en el extractivismo en larga escala, tratan de que ignoremos el hecho de que, al constituirse como instancia máxima de concentración de poder político formal, el Estado no se encuentra apartado de las dinámicas de (re)producción de la vida material.

A continuación, doy el debido destaque a algunos de los aspectos más crudos de las persecuciones políticas, que se materializan en los cuerpos de hombres y mujeres cuyas libertades y posibilidades de expresión se han visto usurpadas en diversas ocasiones, en intentos sistemáticos de inviabilizar la construcción de proyectos de sociedad distintos a lo de la insaciable explotación de los bienes naturales y de las energías humanas.

Inspirada por las reflexiones de Botero (2012), por lo tanto, propongo en este artículo un testimonio reflexivo acerca de prácticas discursivas elaboradas y difundidas a partir de estructuras oficiales de los poderes económicos y estatales, así como de las vivencias y narrativas de sujetos individuales y colectivos, destacando la construcción de nuevos sentidos a la vida política a través del reconocimiento de las luchas diarias de comunidades en resistencia.

\section{El avance del capital y el despojo de nuestros tiempos}

La segunda mitad de los años ochenta del siglo XX ha sido considerada el preludio de un nuevo ciclo de desapropiaciones, represión y resistencias a nivel global, marcada por una significativa elevación de la tasa de explotación del trabajo vivo y por la recuperación de la tasa de ganancia (GILLY; ROUX, 2015). De modo que, ordenamientos jurídicos y políticas institucionales hechas a medida, con vistas a favorecer agentes detentores de poder económico, se han convertido en eficaces herramientas destinadas a la reproducción de mecanismos que exacerban la concentración de riquezas materiales y de control sobre los aparatos estatales.

En ese marco, sea para el beneficio de corporaciones transnacionales y/o de poderosos detentores del capital a nivel nacional, la instrumentalización de los aparatos estatales para fines privados 
atinge niveles de sofisticación abrumadores. En Guatemala, por ejemplo, las maniobras que implicaban la tomada de los estados por grupos fuertemente armados, bajo las premisas de instituciones militares y respaldo de grandes potencias globales en contextos de disputas imperiales, se han ido sustituyendo por una compleja gama de articulaciones que, además del apelo a organismos directamente vinculados a los poderes ejecutivos y sus brazos armados, hacen usos bastante recurrentes y rebuscados de recursos mediáticos, legislativos, jurídicos y financieros.

Para dar cabida a un modelo de desarrollo que trata de legitimarse a través de índices de crecimiento y otros factores de una macroeconomía que, en definitiva, no está diseñada para favorecer los modos de vida y la autonomía de los pueblos, una atención especial es destinada a las etapas más básicas de las cadenas productivas globalizadas. De hecho, con el uso del término "etapas básicas", me refiero a lo que se encuentra en la base de la propia modernidad y de las vías de desarrollo capitalista, siendo, pues, de importancia fundamental. Esas etapas básicas incluyen los llamados recursos primarios, productos de la minería en larga escala, frutos de los agro e hidronegocios, así como la producción de energía y obras de infraestructura que viabilizan la extracción y transporte de mercancías a escala global. La presión sobre los bienes naturales requiere, por lo tanto, control territorial, incidiendo sobre las tierras y los cuerpos en los campos, florestas y aguas del continente. De este modo, verificase un sustantivo agravamiento del sometimiento de América Latina, así como de otras geografías del Sur Global, como históricas proveedoras de materias primas, convertidas en destinos estratégicos de expresivas inversiones transnacionales (SANDT, 2009).

Así, con la expansión del modelo de desarrollo neoliberal como expresión más contemporánea del capitalismo globalizado, la instrumentalización de los aparatos estatales, en beneficio de sectores extractivistas, está cada vez más sofisticada, haciendo uso de una serie de renovados mecanismos discursivos vinculados a prácticas de subordinación y explotación de los pueblos y sus bienes naturales. Se han rediseñado, por lo tanto, prácticas 
de acumulación por despojo, inherentes a la expansión capitalista (HARVEY, 2005).

En este marco, en Guatemala, posteriormente a los Acuerdos de Paz, ${ }^{2}$ la minería en larga escala, cementeras e hidroeléctricas se han expandido como prominentes actividades económicas, juntamente al ya establecido extractivismo agrícola. Estas actividades prolongaron y recompusieron un modelo de dominación ejecutado a través de alianzas entre Estados, empresas nacionales y transnacionales y agentes del capital financiero, que han profundizado desigualdades en el acceso a recursos materiales y al poder político, bajo promesas de desarrollo y crecimiento económico (TZUL, 2014).

En ese marco, ganan espacio medidas represivas abrumadoras que llevan a que hasta la dignidad humana quede fuertemente afectada, con implicaciones físicas, económicas, simbólicas y psicosociales diversas. O sea, los conflictos generados alrededor de la imposición de las referidas actividades económicas se han caracterizado por el uso sistemático de la violencia, incluyendo la militarización de territorios indígenas y la criminalización de autoridades comunales.

Esas violencias son recuerdos de un pasado que sigue vigente, reviviendo heridas de siglos de explotación y ocasionando nuevas fracturas, que condicionan los derechos más fundamentales, así como el porvenir de los pueblos, especialmente en el Sur Global. Destaco, por ejemplo, los múltiples impactos ocasionados por procesos tan violentos como la retirada de comunidades enteras de sus tierras, desproveyéndoles no solo de sus pertenencias materiales y sus medios de vida, sino también de sus espacios de reproducción de la vida en comunidad. La impunidad que aflige a desplazados y desplazadas hiere memorias como las de las

2 Firmados el 29 de diciembre del 1996, los 14 documentos que componen los Acuerdos de Paz en Guatemala pusieron fin a los 36 años de gobiernos dictatoriales resultantes del golpe de Estado del 1954, promovido por la inteligencia estadunidense, en contra del gobierno electo de Jacobo Arbenz Guzmán y sus iniciativas de reforma agraria en el país. El periodo histórico quedó internacionalmente conocido como Conflicto Armado Interno o, según afirman las personas de las camadas más populares del país, especialmente entre los campesinos mayas, los Tiempos de la Violencia. 
víctimas de más de 400 comunidades indígenas masacradas en Guatemala, a lo largo del monstruoso desgobierno de Rios Montt. ${ }^{3}$

Según registros más recientes de la historia de la desumanidad, al no contar con los beneficios del debido proceso, las 111 familias desalojadas de sus hogares en la comunidad Laguna Larga, Petén, el 2 de Junio de 2017, enfrentan condiciones de humanidad denigrantes en la frontera sur de México. Informes de organizaciones de derechos humanos, tales como Voces Mesoamericanas y la Mesa Transfronteriza Migraciones y Género, denuncian la emergencia humanitaria agravada por la falta de acceso a derechos fundamentales, como el agua potable y saneamiento, resultando en una serie de problemas de salud física y psicosociales. Según el informe de esas organizaciones, bajo el muy significativo título Des-esperando en la frontera, evidenciase, además, el desarrollo de más una modalidad de despojo, el "acaparamiento verde", destinado a viabilizar la retirada forzada de comunidades enteras bajo el argumento de la preservación medioambiental ${ }^{4}$ (DES-ESPERANDO..., 2018).

3 Llegando a ocupar el cargo de autoridad máxima en el país durante los años de 1982 y 1983, resultando de un golpe de Estado militar ocurrido el 23 de marzo de1982, el general Ríos Montt llegó a ser condenado, en el 2013, a 80 años por genocidio y crímenes contra la humanidad. La condena se refería a los crímenes cometidos en contra del pueblo Ixil, que tiene sus territorios ubicados en una zona petrolera de la Franja Transversal Norte. Sus vínculos con las élites nacionales quedaron evidenciados en el pedido de anulación de la sentencia por el Comité Coordinador de Asociaciones Agrícolas, Comerciales, Industriales y Financieras (CACIF). La sentencia fue anulada todavía en el 2013. En 2018, Ríos Montt llegó a óbito sin haber cumplido sentencia por los miles de asesinatos, violaciones y demás crímenes cometidos en contra de los pueblos indígenas bajo su gobierno.

4 Contando con un operativo de más de un millar de efectivos de la Policía Nacional Civil y del ejército guatemalteco, la operación se realizó dejando cerca de 700 personas de la comunidad de San Andrés, en Laguna Larga, municipio de La Libertad en Petén, en situación de "violación a los derechos humanos para las personas desplazadas, violación al derecho de asilo y principio de no devolución", incumpliéndose compromisos firmados por los estados de México y Guatemala (ACTIVISTAS..., 2017). Según consta en un informe publicado por la Red Nacional de Organismos Civiles de Derechos Humanos - Todos los Derechos para Todas y Todos, conformada por 84 organizaciones mexicanas, un censo preliminar realizado el día 7 de junio, estimó que había cerca de 450 personas en el campamento ubicado en Campeche, municipio de Candelaria, en la línea fronteriza México-Guatemala (ALARMA..., 2017). 
Según informaciones oficiales del Estado guatemalteco, reiteradas por algunos de los medios de comunicación de mayor circulación en el país (ESCOBAR, 2017), el desalojo estaría siendo motivado por razones de protección medioambiental, favoreciendo la conservación de la biosfera. Sin embargo, medios locales indican que:

[...] las organizaciones de Derechos Humanos de México, ATALC y la Comisión Internacional de Juristas rechazan, además, el argumento de que la comunidad fue desalojada para defender al medio ambiente; señalan que quienes hoy están desplazados no sólo cuidan del lugar que habitan, sino que, además, el Estado guatemalteco tiene otros intereses en la zona, como continuar con la explotación petrolera, de hule, ganadera y con monocultivos de palma aceitera (ORGANIZACIONES..., 2017, [s.p.]).

Sin embargo, las masacres y desapropiaciones masivas no son las únicas medidas implementadas para favorecer la concentración de tierras y otros recursos. El acoso y el engaño son algunas de las maniobras muy ampliamente utilizadas para la obtención de tierras en zonas consideradas estratégicas, para la expansión de los monocultivos, la extracción de minerales metálicos o la producción de energía y el abastecimiento de la industria extractivista. Donde la emergencia de luchas comunitarias logra hacer frente a los avances de dichos proyectos, se recurre a una serie de otras medidas, tales como la apertura de procesos judiciales, que cargan fuertes indicios de criminalización, el encarcelamiento y hasta mismo el asesinato de líderes comunitarios. En palabras de Giraldo (2015, p. 637), al referirse a los crecientes niveles de acaparamiento de tierra a nivel global, especialmente en África, Asia, Europa del Este y América Latina, se están llevando a cabo "diversos mecanismos discursivos y prácticos para desterritorializar a los campesinos, en muchas ocasiones sin necesidad de expulsarlos de sus tierras".

Con todo, el recrudecimiento y/o la sofisticación de los mecanismos de opresión no dejan apenas rastros de destrucción. La sagacidad y la astucia de los agentes y beneficiarios directos de los mecanismos de concentración de poder y riquezas materiales han 
sido fuertemente contrarrestadas por la emergencia de una serie de luchas de los pueblos y sus lazos de solidaridad, compartiendo trayectorias históricas y su caminar de reivindicación de sus identidades colectivas, depositarias de derechos que remeten a su vínculo ancestral con sus tierras y territorios, reflejados incluso en leyes nacionales y referentes jurídicos internacionales, con espacial destaque al Convenio 169 de la Organización Internacional del Trabajo (OIT).

Dando voz y cuerpo a la dialéctica de la conflictividad social, han sido muchos los actos de resistencia frente a los abusos del poderío económico en toda América Latina. Acerca de la extensión y profundización de los conflictos socioambientales, frente a:

[...] la incesante voracidad del capital por subsumir lo común y en general cualquier ámbito que no se encuentre plenamente ceñido o regulado por los ordenamientos de la producción de valor, [observase] la emergencia de múltiples experiencias de resistencia en los territorios de disputa, donde se despliegan significativos procesos de antagonismo e insubordinación social que, en algunos casos, han logrado bloquear los megaproyectos extractivos, y avanzar hacia el acceso y control colectivo de los medios de existencia necesarios para la reproducción de la vida humana y no humana (COMPOSTO; NAVARRO, 2014, p. 33 - 34).

Destaco el caso del territorio Q'anjob'al, ubicado en la zona norte de Huehuetenango, donde incentivos económicos, legales, ideológicos y políticos han atraído significativas inversiones transnacionales en la producción de energía hidroeléctrica (BASTOS et al., 2016; OLIVEIRA, 2016).

En el contexto de articulación de estrategias de explotación de la llamada Franja Transversal Norte, que atraviesa los departamentos de Huehuetenango, el Quiché, Alta Verapaz e Izabal, la zona norte de Huehuetenango ha sido uno de los escenarios donde se ha impulsado la emergencia de movimientos en defensa de la vida y del territorio, recreándose estrategias de resistencia frente a mecanismos arbitrarios direccionados a favorecer la ejecución de inversiones transnacionales y sus múltiples impactos. De 
modo que, desde territorios donde conviven los pueblos mayas Q'anjob'al, Chuj, Mam, Poptí y Akateco, así como la población ladina, se han realizado diversas iniciativas, tales como la realización de consultas comunitarias y procedimientos de autogestión que combinan prácticas políticas innovadoras y referentes organizativos y de tomadas de decisión ancestrales, remetiéndose a la vida comunitaria y a la espiritualidad de los pueblos originarios de la región. ${ }^{5}$

En la definición de sus agendas y alianzas, además de su contenido y estrategias políticas, las iniciativas de resistencia son depositarias de una enorme complexidad, que sobrepasa factores ideológico-partidarios o la disputa por el control del Estado. Se forja un modelo de desarrollo y autonomía que trata de evidenciar el carácter intrínseco de los vínculos existentes entre la humanidad y su entorno; donde las correlaciones entre la (re)producción de la vida material y la conservación medioambiental van mucho más allá de los usos supuestamente racionales de meros artefactos, a los que se atribuye valor económico en la cadena productiva del mercado; donde las relaciones de género no se limitan a la garantía de libertades individuales, sino que forman parte de una trayectoria de luchas en contra de la lógica colonial de control territorial sobre la tierra y sobre los cuerpos, de quienes perciben y forjan sus identidades a partir de sus prácticas comunitarias y del reconocimiento colectivo de las estructuras de dominación que les desnudan de sus derechos más fundamentales.

\section{Estado, desarrollo y empobrecimiento}

Impulsado por los avances de la globalización neoliberal, un determinado modelo de desarrollo se extendió masivamente, a través de relaciones de poder absolutamente asimétricas y

\footnotetext{
5 Las consultas, así como otras medidas de participación política, combinan aspectos de la cosmovisión maya en la tomada de decisiones basadas en el respeto a las autoridades ancestrales y la defensa del bien común, con indicativos de organismos internacionales tales como la OIT y las Naciones Unidas, que apuntan al derecho de autonomía de los pueblos indígenas en el tocante a sus territorios y bienes naturales.
} 
perspectivas ideológicas específicas que tratan de imponerse de manera universal. Inherente a la expansión del referido orden, se han profundizado también los niveles de desigualdad. El régimen de concentración de recursos en el Norte Global se ha mantenido, a través de vínculos estructurales históricos entre oligarcas nacionales y agentes del capital transnacional, con destaque al sector financiero, ampliando su poderío en el control sobre el acceso a recursos materiales y al poder político.

Los discursos desarrollistas oficiales de países del Sur Global siguen centrados en promocionar la creación de parques industriales, los hidro y agronegocios y el extractivismo en larga escala, indicando que mejorías en la calidad de vida de las poblaciones serían los resultados intrínsecos a la expansión de la capacidad productiva, del crecimiento económico y del aumento de la renta per cápita, en América Latina. De esta manera, desde el Cono Sur hasta los límites de la frontera Sur de los Estados Unidos, en territorio mexicano, es posible identificar trazos del recrudecimiento de políticas centradas en la privatización y la explotación masiva de bienes naturales, en detrimento, incluso, de las débiles estructuras y procedimientos de la democracia representativa.

No obstante, pese a los discursos que defienden que el orden neoliberal se caracterizaría por una reducción de las intervenciones del Estado en la economía, su avance se caracteriza por un conjunto de sistemáticas y tendenciosas injerencias, donde la creación de condiciones favorables a los negocios se da en detrimento de derechos colectivos y de la protección del medio ambiente. Así, grandes corporaciones transnacionales y oligarcas locales no solamente colaboran íntimamente con actores estatales, sino que adquieren un fuerte rol en la determinación de políticas públicas y en el establecimiento de marcos legislativos y regulatorios que les sea más favorables (HARVEY, 2000; 2005). Dicho proceso de inserción desigual de diferentes territorios en el seno del mercado globalizado ha ocasionado una serie de impactos políticos y económicos, contribuyendo a la profundización de violencias y desigualdades de múltiples dimensiones.

En Guatemala, según las afirmaciones de Sandt (2009), la firma de la Ley de Minas es un claro ejemplo de este tipo de acomodación 
de intereses estratégicos a través de la instrumentalización del Estado. Aprobada por el Congreso en 1997, bajo presión de compañías mineras transnacionales, el procedimiento se dio sin la realización de consultas públicas, caracterizando un claro incumplimiento de la Constitución, así como de la Convención 169 de la OIT, ratificada en 1996, y el Acuerdo sobre Identidad y Derechos de los Pueblos Indígenas, firmado en 1995, en el marco de los llamados Acuerdos de Paz. La ley tampoco incluye ninguna referencia a los derechos colectivos o a la realización de consultas a comunidades indígenas para la implementación de proyectos en sus territorios ancestrales.

Dada la subida de los precios de minerales metálicos en el mercado y la referida aprobación de un marco legislativo más favorable a los intereses de los inversionistas, de acuerdo a datos oficiales del Ministerio de Energía y Minas (MEM), entre 2003 y 2008, cada año fueron concedidas entre 40 y 51 licencias mineras, alcanzando un total de 262. En paralelo, para atender a la creciente demanda de energía, en 2015, había 65 proyectos hidroeléctricos en todo el país, 21 de ellos en operación.

Frente a ello, lo que se observa es el agravamiento de procesos de empobrecimiento y exclusión. La Encuesta Nacional de Condiciones de Vida (Encovi), del Instituto Nacional de Estadísticas de Guatemala, reveló un aumento de la pobreza, entre 2006 y 2015, la cual pasó del 51 al 59\%. Durante el mismo período, el índice de pobreza extrema nacional subió del 15 al 23\% (DARDÓN GARZARO, 2016; INE, 2015). De acuerdo con datos divulgados por la Agencia Central de Inteligencia de los Estado Unidos (CIA, por su sigla en inglés), en agosto de 2017, la distribución de ingresos en Guatemala seguía altamente desigual, donde los 20\% más ricos logran atingir más del 51\% del consumo general (CIA, 2019). De este modo, verificase la inconsistencia de la supuesta correlación entre el crecimiento de inversiones en actividades extractivas de larga escala y la promoción de mejorías en las condiciones de vida de la población.

En este sentido, como mostraré más adelante, una serie de hechos ocurridos en el norte de Huehuetenango apuntan a que, sumado al establecimiento de constructos ideológicos y marcos 
regulatorios específicos, la creación de un ambiente atractivo a los inversionistas ha conllevado la manipulación estratégica de medios de comunicación corporativos, la disposición de fuerzas policiales y militares, así como medidas judiciales impulsadas no solamente por representantes de empresas involucradas en situaciones conflictivas, sino también desde el propio Estado, a través, por ejemplo, de la actuación de administradores locales y de agentes del sistema de justicia, incluyendo al propio ministerio público.

\section{La construcción del enemigo: del discurso ideológico a los límites de la (i)legalidad}

Para garantizar el control sobre el sistema productivo y el acceso privilegiado a las instituciones que monopolizan el poder político en el país, élites nacionales y locales interesadas en los lucros provenientes de determinadas actividades económicas, tratan de aliñar sus intereses estratégicos a los de grandes corporaciones transnacionales. En ese sentido, apoderándose de los aparatos estatales, en su mayoría hombres ladinos ${ }^{6}$ de media edad, tratan de manufacturar un aparente consenso social acerca de contextos conflictivos, haciendo uso de las instancias encargadas de la elaboración de los discursos oficiales de los poderes públicos, ejerciendo también gran influencia sobre los medios de comunicación manejados por la iniciativa privada.

Un ejemplo bastante ilustrativo se dio en la cobertura del Diario de Centro América TV, de 14 de mayo de 2014 (PRESIDENTE..., 2014), acerca de un encuentro entre el entonces presidente Otto Pérez Molina y representantes del Comité Coordinador de Asociaciones Agrícolas, Comerciales, Industriales y Financieras (CACIF). En la ocasión, se habló de los conflictos ocurridos el día 5 de mayo del mismo año, en virtudes de la instauración de una planta hidroeléctrica en el municipio de San Mateo Ixtatán, uno

\footnotetext{
6 El término ladino tiene una variedad de connotaciones que incluyen la astucia y el disimulo en su actuar, así como una referencia a las personas mestizas de indígenas y blancos que reniegan del idioma y costumbres indígenas. En el contexto guatemalteco, se refiere a las personas que se identifican como herederas de una supuesta blanquitud de origen colonial europea.
} 
de los 8 municipios del norte de Huehuetenango organizados en defensa de sus territorios. ${ }^{7}$ En la dicha noticia del Diario de Centro América TV, se utilizó la palabra "disturbio" para clasificar los hechos identificados como un "enfrentamiento", destacándose lo que supuestamente serían daños ocasionados por "criminales" a las instalaciones de la empresa. El presidente de CACIF, Hermann Girón, declaró además que no había necesidad de generar más diálogo acerca del emprendimiento, ya que, según él, las comunidades de la ubicación apoyaban el proyecto.

Con este ejemplo, puedo observar que, para mantener el status $q u o$, se refuerzan discursos que, desde una posición de poder, tratan de caracterizar como criminales a antagonistas o a una minoría que, al oponerse a los cambios promocionados como la única vía de desarrollo posible, impedirían el avance de proyectos que supuestamente beneficiarían las referidas comunidades. Así como en otras ocasiones, el referido encuentro es también muy simbólico, ya que se presenta como una clara performance, representativa de una sólida alianza entre Estado y empresas privadas. O sea, al contar con la figura del presidente de la República, rindiendo cuentas con el más poderoso ente representativo del empresariado nacional, el evento gana aires de interés nacional. Sin embargo, lo que en verdad se desarrollan son los mecanismos de exclusión, ya que no se confiere ningún espacio para que líderes comunitarios, organizados alrededor de una agenda de oposición a las referidas inversiones, puedan expresar su posicionamiento y tengan voz, en un espacio que claramente hace uso de recursos públicos, sean ellos materiales o simbólicos.

Por lo tanto, la manipulación estratégica de los medios de comunicación es un elemento de fundamental relevancia en ese proceso. Entre sus principales objetivos, tratase de disminuir la credibilidad de las organizaciones sociales frente al conjunto de la sociedad civil e instigar la creencia de que los liderazgos comunitarios estarían conformados por personas que, además

7 San Juan Ixcoy, San Pedro Soloma, Santa Eulalia, San Mateo Ixtatán, San Sebastián Coatán, San Rafael La Independencia, San Miguel Acatán y Santa Cruz Barillas 
de peligrosas, se caracterizarían por promocionar una agenda en contra del desarrollo de la sociedad, disminuyendo así el apoyo popular a iniciativas de organización política protagonizadas especialmente desde las zonas rurales del país. Forjase, pues, una imagen negativa, creando una atmósfera ideológica que serviría de justificación para el potencial uso de fuerzas policiales y militares, sin que haya mayores cuestionamientos de parte del conjunto de la población, especialmente en la capital (BASTOS, 2015; COMPOSTO; NAVARRO, 2014).

Dicha estrategia afectó directamente a autoridades Q'anjob'ales de la zona norte de Huehuetenango, "Autoridades indígenas tratadas como instigadoras y secuestradoras por reclamar derechos ante la explotación de los recursos naturales de sus territorios" (BDH, 2017, p.174). Criminalizados por su actuación política, fueron también blanco de toda una serie de acusaciones racistas, como las del Informe Estructura Criminal, elaborado por la hidroeléctrica Santa Cruz, en mayo de 2014. Según las denuncias sistematizadas por BDH (2017), se expone, entre otras afirmaciones del género, que, en el referido informe:

[...] se le da una connotación criminal a los líderes comunitarios del norte de Huehuetenango para inventar perfiles que luego permitan que la sociedad logre estigmatizar a quienes consideran enemigos. Cada perfil es acompañado de la fotografía y la certificación del Registro Nacional de Personas (Renap) de cada líder comunitario y se refieren a ellos como "personas que acostumbran resolver sus conflictos por medio de la violencia", "señalados por su mal trato y abuso contra los más pobre e indefensos de Barillas", "manipulan el colectivo social para sus propios fines políticos [...] (BDH, 2017, p. 175 - 176).

Sin embargo, la estigmatización es apenas una de las facetas de la manipulación de la opinión pública. Además, dicho documento sirvió de base para las acusaciones orquestadas por agentes del Estado, "incluyendo fiscales de la Fiscalía de Derechos Humanos, que permitieron que estos abusos duraran 16 largos meses; meses que los acusados estuvieron en la cárcel" (BDH, 2017, p. 169). De 
este modo, denunciase el racismo y la discriminación, además de la complicidad y parcialidad de algunos operadores de la justicia, comprometidos con los intereses de empresas mineras e hidroeléctricas.

\section{Militarización de territorios indígenas y judicialización de disputas territoriales}

En paralelo a las prerrogativas de agentes que elaboran y promueven tales discursos oficiales y mediáticos en la promoción de un modelo de desarrollo predatorio y excluyente, se desenvuelven una serie de otras medidas, incluyendo la militarización de territorios indígenas y la criminalización de autoridades ancestrales. Así:

La violencia y la militarización de los territorios son la regla, forman parte inseparable del modelo; los muertos, los heridos y golpeados no son fruto de desbordes accidentales de mandos policiales o militares. Éste es el modo "normal" en que opera el extractivismo en la zona del no-ser (ZIBECHI, 2014, p. 77).

En ese sentido, la actuación tendenciosa del Estado queda aún más evidente con la militarización de territorios que han sido albos de grandes inversiones en áreas como la producción de energía, la minería o los monocultivos agrícolas. Formando parte del proceso de creación del "enemigo interno", como en los llamados "tiempos de la violencia" que caracterizaron el régimen militar en el país, tratase además de responsabilizar a los movimientos de resistencia por la presencia de militares en estas localidades.

En el norte de Huehuetenango, un caso bastante emblemático se dio con la instauración de un estado de sitio en Santa Cruz Barillas, durante la administración de Otto Pérez Molina. Según entrevistas realizadas en el 2015, con miembros del movimiento en defensa de la vida, del territorio, de la madre tierra y de la naturaleza, Sociedad Civil Barillas, la medida llevó a la suspensión del orden constitucional y la ocupación del pueblo por fuerzas militares a lo largo de 18 días, dando cabida a la persecución de 
hombres y mujeres defensores de sus territorios y la aprehensión de autoridades comunales. ${ }^{\mathbf{8}}$

En junio de 2013, mientras el Vice Ministro de Defensa indicaba que el desplazamiento de operativos del ejército hacia el norte de Huehuetenango se destinaba a ofrecer soporte a los agentes policiales de la región, el diputado Amílcar Pop afirmó que la población se encontraba seriamente preocupada con la presencia militar en su territorio. Él cuestionaba, además, el potencial uso de las fuerzas militares como guardias de seguridad de la Hidroeléctrica Santa Cruz, de la compañía Hidralia (MILITARIZACIÓN..., 2014). Las afirmaciones del parlamentar fueron corroboradas en todas las entrevistas realizadas a lo largo de esta investigación.

La presencia militar en áreas civiles de Guatemala, así como de otros lugares de Centroamérica, es comúnmente justificada bajo el argumento de la seguridad nacional o de la guerra en contra del narcotráfico. Sin embargo, la población de las referidas localidades indica que, en efecto, esos operativos no están destinados a cumplir estas labores, ya que no se presta real asistencia a los moradores locales frente a los muy elevados niveles de violencia asociados al crimen organizado, que afecta seriamente a la región centroamericana, no incidiendo efectivamente en el combate o la prevención de actividades criminales.

En este sentido, además de cumplir con un papel represivo en el control de los flujos migratorios en la región, queda muy evidente que el uso de las fuerzas armadas en beneficio de intereses privados no ha sido un hecho excepcional en Guatemala. En el caso del norte de Huehuetenango, además de que las fuerzas armadas hayan sido utilizadas como mecanismo de seguridad privada de empresas, incluso para custodiar maquinarias, se ha denunciado también prácticas de intimidación y persecución a la población local.

En una serie de artículos publicados por Quimy De León, Francisco Lucas, Nelton Rivera y Santiago Bastos, se han reportado algunos de los mecanismos de represión perpetrados en los municipios de Santa Eulalia, San Mateo Ixtatán y Santa Cruz

Cf. Abbott (2015) y Oliveira (2016). 
Barillas. (BASTOS et al., 2016) Los autores también destacan la militarización y la criminalización como ejes centrales de represión a la emergencia de movimientos de resistencia, siendo las persecuciones y detenciones arbitrarias algunas de las prácticas más comúnmente empleadas. Tales medidas han afectado directamente a pueblos indígenas, así como a la población mestiza excluida de los círculos de poder en el país, organizados frente a la implementación de actividades que se establecen en contra de la voluntad de sus comunidades, invadiendo sus territorios y amenazando sus modos de vida y sistemas productivos.

Resalto que los impactos del uso arbitrario y parcial del poder estatal en contra de esas comunidades se reflejan en los diversos ámbitos. La persecución criminal de autoridades ancestrales trata de poner en riesgo los procesos de construcción de autonomías locales y la soberanía de los pueblos. Por ejemplo, las muy graves acusaciones que pueden llegar a implicar pena de muerte, tales como el plagio o secuestro, tienen por objetivo inyectar miedo en las poblaciones, tratando de inviabilizar su organización política. ${ }^{9}$

Otro hecho significativo, declarado durante entrevistas en los municipios mencionados, fue la existencia de otras órdenes de prisión en contra de autoridades comunales. Viéndose forzados a permanecer en sus pueblos, bajo el riesgo de ser encarcelados, las familias de muchos de esos hombres y mujeres han tenido sus fuentes de renta limitadas, ya que no han podido, por ejemplo, realizar actividades comerciales en otras localidades.

Las precauciones se deben a la cruda realidad de los hechos, ya que, considerando solamente el periodo de mi estancia en el país, en el 2015, apenas de la zona norte de Huehuetenango, 10 líderes comunitarios se encontraban en las cárceles de la cabecera departamental o de la capital. Desde Barillas: Francisco Juan Pedro, Adalberto Villatoro, Arturo Pablo, Saul Méndez, Rogelio Velásquez,

9 El encarcelamiento implica también enormes dificultades para que familiares de las personas arrestadas puedan ofrecerles el apoyo necesario y garantizar la supervivencia de sus familias. Desde el norte de Huehuetenango, arcase también con los elevados costes de desplazamiento para realizar visitas en los centros de detención, ubicados en la cabecera departamental o en la capital. 
Mynor López y Hermitanio López Reyes. Desde Santa Eulalia: Rigoberto Juarez Mateo y Domingo Baltasar, además del abogado Pedro Rubel Toledo y Toledo. Estas personas fueron convertidas en presos políticos, por su actuación de liderazgo en movimientos de resistencia. Ellos, juntamente a otros hombres y mujeres, actúan en contra de la implementación de proyectos extractivos y la usurpación de sus aguas y tierras para la producción de energía, que, además de no traer beneficios para la población local, no cuentan con el debido consentimiento de sus comunidades.

Los crímenes supuestamente cometidos por ellos no pudieron ser comprobados, dando más indicativos de que los procesos judiciales eran inconsistentes y arbitrarios (BASTOS, 2015). Rigoberto Juarez Mateo y Domingo Baltasar, por ejemplo, habían sido acusados de plagio o secuestro, por su presunta participación durante un conflicto en el Centro de Administración de Justicia (CAJ) de Santa Eulalia, entre los días 19 y 20 de enero de 2015. Los hechos se habrían desencadenado posteriormente a la prisión de dos jóvenes de la localidad de Pojom, en el municipio de San Mateo Ixtatán, también en el norte del departamento. Ambos formarían parte de las movilizaciones en contra de los proyectos hidroeléctricos de la compañía Proyectos de Desarrollo Hídrico S.A., en la referida localidad. Según entrevistas que realicé a finales de 2015, estos dos líderes comunitarios habían sido arbitraria y violentamente arrestados y conducidos a la cabecera departamental, ocasionando el levantamiento de miembros de su comunidad, que se desplazaron hacia el CAJ de Santa Eulalia, para pedir aclaraciones acerca del ocurrido. Por un lado, se logró comprobar que Domingo Baltasar tampoco se encontraba en el local de los hechos. Por otro lado, indicase que, en la ocasión del conflicto ocurrido en el CAJ de Santa Eulalia, Rigoberto ejercía el rol que le fue conferido por la asamblea comunal, actuando en la mediación correspondiente a su reconocido papel como autoridad Q'anjob'al.

En el marco de la resolución de algunas de las acusaciones imputadas a Rigoberto Juárez, la jueza Iris Yassmin Barrios Aguilar declaró en su voto razonado en el Tribunal Primero de Sentencia Penal, Narcoactividad y Delictos, el 22 de julio de 2016, que: 
Respecto al señor RIGOBERTO JUÁREZ MATEO, dicen que cometió coacción, yo digo que no; porque no le creo al señor David Yurandi Rivera, el secretario, que nos vino a mentir aquí al tribunal y tampoco le creo a la señorita Sandra Geraldini Pascual que nos vino a contar un episodio muy fuera de la realidad, bastante inverosímil. Por otra parte el Juez Marlon Interiano, que supuestamente es a la persona a quien se coaccionó, vino a la sala pero se acogió a su derecho de no declarar. Por lo tanto donde está la coacción, ¿dónde está? (...) Creo en su inocencia. (...) Según el estudio de la doctora Tzul Tzul y los otros estudios que se presentaron, se dijo que Rigoberto Juárez Mateo es autoridad ancestral, por lo que actúa como mediador, y que la autoridad ancestral va caminando con la comunidad, que lo representa, que lucha por sus intereses y algo muy hermoso de la cosmovisión maya que he aprendido en este debate, que las autoridades deben reconocer la voluntad de las asambleas. Es algo que nosotros también tenemos que aprender (BDH, 2017, p. 89 - 90).

En su trabajo de peritaje referente a la criminalización de autoridades ancestrales de la zona norte de Huehuetenango, Gladys Elizabeth Tzul Tzul (BDH, 2017) destacó el sentido de la producción de la autoridad como parte de los pactos de tramas comunales que involucran a hombres, mujeres, niños y niñas en la composición de asambleas, que ejercen el papel fundamental de interpelar, interrogar y apoyar a sus autoridades. Diferentemente de las estructuras de poder liberal y su concepción acerca del liderazgo: "la autoridad comunal es rotativa, la nombra una asamblea, es una persona que no tiene pago, pero debe rendir cuentas con a la asamblea anual y permanentemente. Y no únicamente cuentas financieras, sino de actos políticos" (BDH, 2017, p. 34). En ese sentido, la defensa de los acusados tiene como base de argumentación la legitimidad del rol ancestral de autoridades comunales, actuando en la mediación y resolución de conflictos.

Sin embargo, he podido observar una serie de otros casos que revelan que las estrategias de explotación y dominación de los pueblos y sus territorios sobrepasaron los límites de la legalidad. 
Según declaraciones de investigadores, autoridades y hogareños de Santa Cruz Barillas, especialmente hombres y mujeres que también sufrieron amenazas y persecuciones, Andrés Pedro Miguel fue asesinado en las proximidades de la localidad de Poza Verde, el primer de mayo de 2012. Iba en compañía de Pablo Antonio y Esteban Bernabé y ambos quedaron heridos. Este mismo año, Esteban fue también arrestado y torturado. Además de posicionarse en contra de las instalaciones de una hidroeléctrica de la empresa española Hidralia, Andrés Pedro y Pablo Antonio se habrían recusado a vender sus tierras al emprendimiento. Indican además que trabajadores y representantes de la empresa, así como el Estado guatemalteco, incluyendo el Ministerio Público, serían los responsables directos por las agresiones perpetradas en la comunidad. Juan Roberto Garrido, encargado del departamento de desarrollo social de la empresa Hidro Santa Cruz - Hidralia, fue apuntado por moradores locales como responsable por los crímenes de intimidación, detención ilegal y extorción. También destacan la participación de Luis Castro Valdivia y su hermano David Castro Valdivia. Ambos fueron formalmente acusados en España, por una serie de crímenes relacionados a irregularidades en la producción de energía renovable. El caso quedó conocido como "trama enerxética", en gallego. ${ }^{10}$ Ninguno de ellos fue formalmente indiciado por los crímenes ocurridos en Barillas. ${ }^{11}$

Es decir, desde que las poblaciones locales pasaron a organizarse para expresar pacíficamente su oposición y denunciar la imposición de actividades por ellas consideradas dañinas a sus procesos de desarrollo y reproducción de la vida comunitaria, las persecuciones y los procesos de criminalización, o la conversión de defensores de sus territorios en criminales a los ojos del Estado, han sido una estrategia bastante usual, habiendo sido denunciada también por juristas, académicos, periodistas y defensores de los derechos humanos. (BASTOS, 2015; UDEFEGUA, 2014; 2015)

10 En agosto de este mismo año, un grupo de feministas organizó una demonstración en frente a una de las oficinas de la compañia, en Galicia, en solidaridad con la lucha de las comunidades mayas, en Barillas, Guatemala. Ver más detalles sobre la "trama enerxética" en A trama... (2007) y Pérez Pena (2012). 11 Más detalles acerca de las trayectorias de los líderes comunitarios de Barillas pueden ser encontrados en Udefegua (2014) y Oliveira (2016). 
En entrevista concedida el 17 de octubre del 2017, en la Ciudad de Guatemala, Rigoberto Juárez, una de las autoridades Q'anjob'ales más emblemáticas de Guatemala, hace un breve repaso del funcionamiento del referido mecanismo de subordinación y violación de derechos:

Lo más claro y visible es la persecución judicial, la criminalización y las ordenes de captura, el encarcelamiento de autoridades, entre hombres y mujeres, por el solo hecho de defender el territorio. ¿Pero quién es el que impulsa esas agresiones en nuestros territorios? Es el estado mismo. ¿Por qué? Porque es el estado el que aprueba una ley, por ejemplo, la ley de Energía y Minas. Entonces, las empresas llegan con el permiso del Ministerio de Energía y Minas para sacar, extraer los bienes naturales por los cuales fueron cedidas sus licencias a una empresa, sin el consentimiento de nuestros pueblos. Entonces eso no es una acción cualquiera, es una acción de agresión. Porque está utilizando sus leyes en contra de nuestros pueblos. Y en nuestros pueblos hay formas propias de resguardo comunitario y eso para el estado no existe. (...) Cuando nuestro rol es decir: nosotros no vamos a permitir que se lleven nuestros bienes naturales, que se los extraigan. (...) Y con la peña, digamos, de las empresas, van y entran ya las fuerzas de seguridad para irrumpir en las comunidades y obligar a la gente a que acepte las empresas. Entonces, el tono de la agresión ya sube más. Ya hay la agresión física. (...) Hay agresiones psicológicas, hay agresión económica, hay agresión cultural y hay agresión física. Y las agresiones más fuertes que hemos podido ver ahora es cuando se utilizan las leyes para criminalizar, el hecho de que una autoridad es llevada a la cárcel por el solo hecho de defender su territorio ya no solamente es una agresión, ya incide fuertemente en una política de exterminio. Porque con el hecho de que la gente se calle, están exterminando su sentido de pertenencia al territorio, entonces la forma de agresión es tan sutil que a veces no se ve. Por eso es que nosotros estamos denotando, ¿Qué es agresión? 


\section{De la inacción a la injerencia}

La instrumentalización del poder estatal es, por lo tanto, parte de la lógica extractivista asociada al modelo neoliberal de acumulación capitalista (ZIBECHI, 2014; BASTOS, 2015; OLIVEIRA, 2016). El nivel de descaro y sofisticación que caracteriza los usos de los aparatos estatales para el favorecimiento directo de empresas privadas va desde la elaboración de leyes hechas a medida, para atender a las demandas de grandes corporaciones transnacionales y/o del conglomerado de oligarcas nacionales, institucionalmente representadas por el CACIF, hasta la militarización de territorios indígenas y persecución a autoridades comunales.

Entre los trabajos de periodismo investigativo realizados en Guatemala sobre la materia, quisiera llamar la atención para una de las publicaciones de Jeff Abbott (2015). En su artículo, indica que la moderna expansión de proyectos hidroeléctricos de compañías privadas en Centroamérica corresponde al Plan PueblaPanamá, liderado por el entonces presidente de México, Vicente Fox, a principios de los años 2000. En 2006, en virtud de escándalos de corrupción, dicho plan habría pasado a llamarse Plan Mesoamérica. La propuesta formaría parte de una campaña del Banco Mundial, con vistas a crear un mercado energético que conectara la infraestructura eléctrica de los países centroamericanos, así como las carreteras y los sistemas de telecomunicaciones, favoreciendo la circulación de bienes y servicios. Estaría, por lo tanto, directamente vinculado a la agenda neoliberal y al Tratado de Libre Comercio (TLC) firmado por la República Dominicana, Centroamérica y Estados Unidos de América (DR-CAFTA, por su sigla en inglés) (ABBOTT, 2015). Habiendo sido ratificado por el Congreso guatemalteco en 2005, el referido tratado internacional recibió una serie de críticas, al no haber sido sometido a un proceso de debate que incluyera sectores de la sociedad civil.

En lo que se refiere a los derechos de las poblaciones indígenas y tribales, los Estados centroamericanos se han caracterizado por una aparentemente sutil contradicción, entre la omisión deliberada y la acción truculenta. Tras un manto de legitimidad y validez universal, en lugar del glorioso ente supuestamente forjado con el 
triunfo de Westfalia, ${ }^{12}$ me deparo con un conglomerado de instituciones podridas desde el interior de sus nódulos vitales. Aunque mantenga su estatuto autoproclamado y el reconocimiento de sus pares, que conforman la nombrada comunidad internacional, y siga siendo proclamado por los académicos de gabinete de diversas partes, lo que puedo averiguar de su actuación es la sistemática y sistémica negación del papel que le fue formal y arbitrariamente atribuido, como representante máximo de los intereses de las poblaciones que habitan los territorios que se encuentran bajo su jurisdicción y control militar.

En Guatemala, es a través de sus órganos reguladores, fiscalizadores y represores, tales como el Congreso Nacional, el Ministerio Público, el Ministerio de Minas y Energía y las fuerzas policiales y militares, que se ejecuta el poder atribuido a los más elevados puestos de mando del Estado, ocupados junto al gabinete presidencial. Verifico, por ejemplo, que, travestida de seguridad y protección de derechos frente a los ataques de bandos agresivos, lo que se realiza en los salones de los edificios públicos, quedando parcialmente reflejados en los documentos y páginas virtuales de sus instituciones, son verdaderos espectáculos mediáticos destinados a la promoción de un padrón de explotación de los bienes naturales que se hace llamar desarrollo. Hecha con los recursos económicos y el soporte institucional del Estado, esta sistemática y velada promoción de prácticas de violación y despojo suele culminar en actuaciones truculentas y graves violaciones de derechos.

Conformando la Franja Transversal Norte de Guatemala, la zona norte de Huehuetenango es considerada de interés estratégico para la explotación minera y petrolera. Según el periodista Gustavo Illescas (2015a), los intentos de apropiación de estos y otros bienes naturales en el área han provocado la emergencia de una serie de escenarios conflictivos cargados por la desconfianza, el racismo y otras formas de violencia, profundizando las heridas de guerra, del "tiempo de la violencia", llevando al desplazamiento de poblaciones indígenas y dividiendo las comunidades locales.

12 Como marco del derecho internacional, el tratado de Westfalia hace referencia a la construcción del consenso respecto al Estado-nación y a la soberanía estatal, a mediados del siglo XVII. 
En ese marco, destaco, por ejemplo, el relato de Illescas (2016), según el cual registrase que la populación del área Ixquisís, en San Mateo Ixtatán, sufrió amenazas de funcionarios de la compañía Promoción y Desarrollos Hídricos S.A. de la empresa española Hidralia. Él también destaca que la obra incluiría la construcción de las plantas hidroeléctricas San Andrés y Pojom II, que pertenecerían a la familia Rodas Marzano. La construcción estaría a cargo de la empresa Israelí Solel Boneh, habiendo recibido préstamos del Inter-American Development Bank y del Inter-American Investment Corporation (ICC).

Así, ese tipo de inversiones cuenta con el soporte de articulaciones muy complejas, compuesta por una diversidad de actores que van desde milicias que manejan la seguridad privada de oligarcas locales, a gigantescas corporaciones financieras internacionales, que se encuentran vinculados a los territorios ancestrales de los pueblos de Huehuetenango y de otras zonas del país con la única finalidad de sacarles beneficios económicos/financieros (OLIVEIRA, 2016). En este sentido, no puedo atribuir un carácter aislado a la situación conflictiva mencionada, ya que circunstancias muy similares, caracterizadas por el uso bastante sistemático de diversas formas de violencia, han sido registradas en otros municipios del país, donde emergen fuertes movimientos de oposición a inversiones transnacionales en la industria minera y la producción de energía (SANDT, 2009; OLIVEIRA, 2016).

O sea, el avance de dichos procesos no se ha dado sin conflictividad social y resistencias. Destaco, por ejemplo, las iniciativas de resistencia de la comunidad de La Puya, frente a la Mina Marlín (SANDT, 2009; BASTOS, 2015), el caso de las doce comunidades kaqchikeles contra la Cementera San Gabriel (TZUL, 2014) y el avance de la Palma africana en Alta Verapaz, entre otras. Sea por los niveles de violencia perpetrados por las fuerzas del Estado, sea por las estrategias de lucha y conquistas de comunidades, incluyendo la anulación de licencias, o incluso por su ubicación geográfica, los alusivos movimientos de resistencia son referencias importantes para otros colectivos, que se suman a las voces que cuestionan no solo la legitimidad sino también la legalidad de las intervenciones estatales y de corporaciones privadas en sus territorios. 
En ese marco, Rigoberto Juárez hace referencia a la retomada de la autonomía de los pueblos frente al rol del estado guatemalteco en la sistemática práctica del despojo de territorios maya:

El esfuerzo que estamos haciendo hoy es nuevamente recuperando la estructura ancestral de autogobierno que existía, partiendo de que el estado guatemalteco es un estado impuesto, no corresponde, no nos representa. Ojalá, bueno, desde la independencia, por decir, ojalá que hubiera funcionado esa independencia para que los pueblos tuviésemos más posibilidades de participación, bueno, nos sentiríamos parte del estado. Al contrario el estado ha servido más para generar desigualdades sociales y el estado ha funcionado para el despojo de nuestras tierras y territorios, las cuales pasan a las manos de los grupos de poder económico en el país, la oligarquía. Y la oligarquía prácticamente se está ampliando sus pertenencias mediante los despojos. Y hoy una vez más hay una política, una estrategia de despojo de nuestras tierras y territorios porque ahí están ubicados los bienes estratégicos para el desarrollo económico de estas familias. Cuando decimos bienes estratégicos hablamos del agua, hablamos de los minerales metálicos, hablamos de las tierras productivas que van a servir para la siembra de los monocultivos. Entonces prácticamente hay una estrategia de desplazar a los pueblos de sus territorios y quedarse con ellos. De ese cuento es que la única forma que nosotros vemos por hoy para volver a recuperar nuestra dignidad como pueblos es mediante nuestro autogobierno. El autogobierno de los pueblos, su autodefinición como tal y su autodesarrollo. Y ese es el trabajo que estamos tratando de impulsar como Gobierno Ancestral Plurinacional.

\section{Los caminos de la resistencia en la (re)construcción de la política comunitaria}

Frente al referido escenario, en el departamento de Huehuetenango, se realizaron varias iniciativas organizativas y de fomento a la participación política local, incluyendo la utilización de radios comunitarias como vehículo de difusión de información 
no corporativa, acerca de los referidos emprendimientos y sus impactos. ${ }^{13}$ Se realizaron también consultas comunitarias de buena fe, como instrumento de participación en las tomadas de decisión, gestionado por las propias comunidades. Según informaciones de la antropóloga Cecilia Mérida, ${ }^{14}$ algunas de las consultas, como en el caso de Barillas, se dieron previamente a la llegada de las empresas, basadas en la experiencia de otros pueblos que sufrieron los impactos de emprendimientos semejantes en otras zonas del país. Con el objetivo de reflejar el posicionamiento del conjunto de cada comunidad, las consultas se hicieron en espacios públicos, contabilizando un masivo "no" a la instauración de empresas extrajeras dedicadas a la minería y a la producción de energía hidroeléctrica ${ }^{15}$.

Además de articularse a prácticas ancestrales, el derecho a la consulta libre e informada forma parte de los direccionamientos establecidos en el Convenio 169 de la OIT, componiendo así una herramienta legalmente reconocida en el orden de la democracia liberal. De ahí, surge también el debate acerca de su reglamentación. Defendida por representantes del CACIF, la medida viene siendo altamente criticada por organizaciones sociales, como, por ejemplo, la Asociación de Abogados Mayas, que identifica, en la propuesta, una forma de limitar las prerrogativas establecidas en los convenios internacionales y vigentes en el marco legislativo guatemalteco.

Destaco aún que, en Barillas, la movilización popular en contra de los referidos emprendimientos se ha organizado en una zona llamada Poza Verde, convirtiéndose en el área más emblemática de la reciente emergencia de un movimiento social en el municipio, estando ubicada justo en la entrada de las tierras adquiridas por Hidralia:

13 Resalto que la Radio Comunitaria de Santa Eulalia se convirtió, además, en un importante espacio de disputa política en el pueblo, habiendo sido cerrada por el alcalde local, bajo el argumento de ausencia del registro formal de sus actividades, mientras las autoridades comunales argumentan que su cierre arbitrario de dio en el marco de las diversas iniciativas de persecución política a opositores y liderazgos populares.

14 La entrevista con Cecilia Mérida fue realizada durante mi estancia de investigación en el 2015, en el municipio de Santa Cruz Barilla, durante un evento en apoyo a los presos políticos de Huehuetenango.

15 Cf. Illescas (2015b). 
La resistencia Nuevo Amenecer surgió luego de que el gobierno del expresidente Otto Pérez Molina impusiera un Estado de Sitio en Santa Cruz Barillas en mayo de 2012, donde se realizaron violaciones a los derechos humanos, incluyendo detenciones ilegales masivas contra liderazgos del movimiento q'anjob'al y mestizo que se opone a los proyectos hidroeléctricos de la empresa Hidro Santa Cruz, S.A., propiedad de la empresa transnacional española, Hidralia. (Illescas, 2016)

El lugar es considerado especialmente relevante no sólo para evitar la entrada de maquinarias de la empresa y por crear un espacio común de referencia territorial permanente, sino por ser símbolo de resistencia, frente a un proyecto que se impone en detrimento de los intereses de la población local, y por ser espacio de celebración de ceremonias de la espiritualidad maya y de la cosmovisión de sus pueblos.

De modo transversal, las reflexiones aportadas desde los feminismos comunitarios es otro riquísimo ejemplo de construcciones colectivas que parten de una epistemología que se hace política a través de las luchas diarias de mujeres, especialmente indígenas, que reivindican el reconocimiento de la existencia de miradas diferenciadas frente a la tierra y al cuerpo, entendidos como territorios en disputa, en el marco de estructuras coloniales y patriarcales todavía dominantes (CABNAL, 2010).

Sumado a ello, a través del protagonismo de sus autoridades comunales, desde los municipios del norte de Huehuetenango, en territorio $Q^{\prime}$ anjob'al, destaco el Gobierno Plurinacional presentándose como una iniciativa de gestión comunitaria, basada en principios de participación política que cuestionan los límites y la propia legitimidad de la democracia representativa de corte liberal vigente. Dicha articulación estaría, por lo tanto, basada en lo que Gladys Tzul Tzul (2014) identifica como parte de las estructuras ancestrales de poder bajo los conceptos de autoridades ancestrales y del sistema de justicia ancestral, actuando en la resolución de conflictos a través del favorecimiento del bien común y de la armonía comunitaria. 
En diálogo con las terminologías que marcan el monopolio del derecho a la autonomía territorial, como estando pautada por la conformación del Estado-nación, emerge la reivindicación del reconocimiento de la diversidad de nacionalidades que estarían bajo el control del Estado guatemalteco en contra de su voluntad, haciéndose necesario, por lo tanto, el reconocimiento de estancias de poder que correspondan a las respectivas reivindicaciones de soberanía nacional. ${ }^{16}$ En palabras de Rigoberto Juárez:

No estamos hablando de una formación. Nuestros Gobiernos han estado ahí. Los pueblos, las naciones, tienen sus gobiernos proprio, desde hace siglos, de hace miles de años, ¿verdade? El problema es que el Estado impuesto ha venido a desconocer esas formas de gobierno propias, con la idea de que nosotros nos sujetemos al mandato, a lo que ellos decidan sobre nuestros territorios. ¿Qué hacemos? Volver a visibilizar a esos propios gobiernos. Visibilizarnos. Decir que aquí están nuestros propios gobiernos, que son los que han ejercido sus funciones para armonizar las relaciones entre nuestros pueblos, no es el Estado guatemalteco. Entonces, ante a la escalada de agresión fuerte que hemos recibido durante estos los últimos anos, ¿A quién acudimos? $¿$ Acudimos a las autoridades del estado guatemalteco que son los que nos agreden? ¿O qué otra forma de defendernos? Entonces de ahí hacemos la mirada hacia nuestros pueblos. Nuestras autoridades propias aquí están. Lo único que tenemos que hacer entonces es fortalecer. Fortalecer la capacidad de estas autoridades del ejercicio del poder local, poder territorial. Y eso es lo que hemos hecho.

Sin embargo, resalto que la conformación de las referidas estrategias colectivas de resistencia frente al avance del régimen de explotación y dominación capitalista no se da de forma homogénea y desproveída de conflictos internos. Divergencias ocurren, por ejemplo, en la identificación de diferentes formas y espacio de participación política, sea apostando por la vía electoral, sea

16 El debate al rededor del concepto de multiculturalismo sería un equivalente teórico de esa temática, trabajada desde otras geografías y contextos sociohistóricos. 
por diferentes rutas en la construcción de un Estado plurinacional, favoreciendo espacios de autonomía cada vez más amplios, a través de la eliminación de determinados vínculos con las estructuras del Estado nacional guatemalteco.

\section{Consideraciones finales}

Es en la dialéctica de conformación del poder, pautada por la (des)construcción de relaciones de subalternidad, que sitúo a los conflictos puestos en evidencia en Guatemala. Estos conflictos caracterizan una disputa que va mucho más allá del control sobre las riquezas materiales y las instituciones del Estado, pues se trata de caminos civilizatorio distintos. Por un lado, en el entorno socioambiental, hay posibilidades de rentabilidad y acúmulo de capital, desde una perspectiva que cela prioritariamente por el derecho a la propiedad privada sobre los medios de producción. Por otro lado, gana mayor visibilidad el caminar de aquellos y aquellas que se basan en la sacralización de la interacción humana con su territorio y con los bienes que configuran y garantizan la continuidad de la vida, a quienes comúnmente nos referimos como pueblos originarios o comunidades tradicionales. Sus cosmovisiones no comparten de la sacralización de la razón instrumental y de la celebración del individuo, tal y como se marcó la idealización de la modernidad occidental y su modelo de desarrollo.

Esas y otras iniciativas son cunas de osadas y promisoras propuestas de desarrollo, centradas en valores comunitarios y en la búsqueda de equilibrios en la reproducción de la vida material, social y espiritual, priorizando relaciones de solidaridad a nivel local. Sin caer en actitudes de romantización de los pueblos originarios, desde la academia, así como de otros espacios donde la producción de conocimiento cuenta con plataformas institucionales de gran impacto, influyendo incluso en la elaboración de políticas públicas, se hace necesario ampliar nuestros horizontes, potencializando diálogos más abiertos, junto a quienes desafían las construcciones epistemológicas y ontológicas cristalizadas en las rutas del colonialismo, forjando caminos de resistencia desde un sentipensar cotidiano, (re)creando vínculos identitarios 
y nuevos sentidos a la política y a la construcción de las autonomías, más allá de los límites del Estado concebido en el marco de la tradición liberal.

\section{REFERENCIAS}

ABBOTT, J. Transnational Companies Driving Deadly Conflict in Guatemalan Indigenous Territory. Truthout, [on line], 15 abr. 2015. Disponible en: $<$ https://truthout.org/articles/transnational-companies-driving-conflictin-guatemala-indigenous-territory/>. Acceso en: 17 abr. 2016.

ACTIVISTAS reportan éxodo de 700 guatemaltecos a México. Voces mesoamericanas, Chiapas, 31 jul. 2017. Disponible en: <https:// vocesmesoamericanas.org/prensa/acciones-urgentes/activistasreportan-exodo-700-guatemaltecos-a-mexico/>. Acceso en: 04 ago. 2019.

ALARMA y preocupación ante condiciones de la comunidad Laguna Larga, Petén, desplazada forzadamente en la frontera con México. REDTDT, [on line], 9 jun. 2017. Disponible en: <http://redtdt.org.mx/?p=8732>. Acceso en: 9 jun. 2019.

A TRAMA das renovábeis: negocio para uns poucos, impactos para todos. Asociación para a Defensa Ecolóxica de Galiza, Galicia, 11 mai. 2007. Disponible en: <http://adega.gal/info/090121joomla/areas-tematicas/ enerxia/54-a-trama-das-renovabeisnegocio-para-uns-poucos-impactospara-todos> Acceso en: 17 abr. 2016.

BASTOS, S. Huehuetenango ¿ingobernable? el papel de los medios en la criminalización de la lucha por el territorio. Prensa Communitaria Km. 169, Guatemala, 12 dic. 2015. Disponible en: <https://comunitariapress. wordpress.com/2015/12/12/>. Acceso en: 17 abr. 2016.

BASTOS, S. et al. La movilización comunitaria y la represión estatal. Prensa Comunitaria Km. 169, Guatemala, 29 mar. 2016. Disponible en: $<$ https://comunitariapress.wordpress.com/2016/03/29/la-movilizacioncomunitaria-y-la-represion-estatal/>. Acceso en: 17 abr. 2016.

$\mathrm{BDH}$. Extractos de la sentencia parcialmente absolutoria de las autoridades ancestrales de Santa Cruz Barillas y Santa Eulalia de Huehuetenango y otras resoluciones del caso. Ciudad de Guatemala: Editorial Serviprensa, 2017.

BOTERO, P. Investigación y acción colectiva "IAC": una experiencia de investigación militante. Utopía y Praxis Latinoamericana, Maracaibo, n. 57, p. $31-47,2012$. 
CABNAL, L. Acercamiento a la construcción de la propuesta de pensamiento epistémico de las mujeres indígenas feministas comunitarias de Abya Yala. Las Segovias: ACSUR, 2010.

CIA - Central Intelligence Agency. The World Fact Book: Guatemala. [s.l.]: [s.n.], 2019. Disponible en: <https://www.cia.gov/library/publications/ the-world-factbook/geos/gt.html>. Acceso en: 04 ago. 2019.

COMPOSTO, C.; NAVARRO, M. L. Claves de lectura para comprender el despojo y las luchas por los bienes comunes naturales en América Latina. In: (comp.). Territorios en disputa: despojo capitalista, luchas en defensa de los bienes comunes naturales y alternativas emancipatorias para América Latina. Ciudad de México, D. F.: Bajo Tierra Ediciones, 2014. p. $33-75$.

DARDÓN GARZARO, B. ¿Hay más o menos pobreza?: encuesta enfrenta a expertos. Prensa Libre, Ciudad de Guatemala, 21 ene. 2016. Disponible en: <https://www.prensalibre.com/economia/encuestaenfrenta-a-expertos/>. Acceso en: 04 ago. 2019.

DES-ESPERANDO en la frontera: informe de la situación de la comunidad Laguna Larga a seis meses de su desplazamiento forzado. Voces Mesoamericanas, Chiapas, 10 ene. 2018. Disponible en: <https:// vocesmesoamericanas.org/blog/multimedia/audios-programa-especialdes-esperando-en-la-frontera-la-situacion-la-comunidad-laguna-larga-a6-meses-del-desplazamiento-forzado/>. Acceso en: 04 ago. 2019.

ESCOBAR, R. PNC desaloja a 70 familias de Laguna Larga, área protegida de Petén. Prensa Libre, Guatemala, 5 jun. 2017. Disponible en: <http:// www.prensalibre.com/ciudades/peten/recuperan-laguna-larga-areaprotegida-de-peten> Acceso en: 5 de junio de 2017.

GILLY, A. G.; ROUX, R. R. El tiempo del despojo: siete ensayos sobre un cambio de época. Ciudad de México, DF: Itaca, 2015.

GIRALDO. O. F. Agroextractivismo y acaparamiento de tierras en América Latina: una lectura desde la ecología política. Revista Mexicana de Sociología, Ciudad de México, D.F., v. 77, n. 4, p. 637 - 662, 2015.

HARVEY, D. Spaces of Hope. Edinburgh: University Press, 2000.

A Brief History of Neoliberalism. Oxford: University Press, 2005.

ILLESCAS, G. ¿Qué hacen tres líderes comunitarios de Barillas en el Preventivo de la Zona 18? Centro de Medios Independientes, Ciudad de Guatemala, 2015a. Disponible en: <https://cmiguate.org/que-hacentres-lideres-comunitarios-de-barillas-en-el-preventivo-de-la-zona-18/>. Acceso en: 17 jun. 2016. 
Consulta Comunitaria No. 29 de Huehuetenango: Malacatancito Presente. Centro de Medios Independientes, Ciudad de Guatemala, 2015b. Disponible en: <https://cmiguate.org/consulta-comunitaria-no29-de-huehuetenango-malacatancito-presente/>. Acceso en: 17 abr. 2016.

Caravana de la dignidad: por las resistencias y la libertad de los presos políticos del norte de Huehuetenango. Centro de Medios Independientes, Ciudad de Guatemala, 2016. Disponible en: <https:// cmiguate.org/caravana-de-la-dignidad-por-las-resistencias-y-la-libertadde-los-presos-politicos-del-norte-de-huehuetenango/>. Acceso en: 17 abr. 2016.

INE-Instituto NacionaldeEstadística Guatemala. RepúblicadeGuatemala: encuesta nacional de condiciones de vida 2014 - principales resultados. Ciudad de Guatemala: INE, 2015. Disponible en: <https://www.ine.gob.gt/ sistema/uploads/2015/12/11/vjNVdb4IZswOj0ZtuivPIcaAXet8LZqZ.pdf>. Acceso en: 04 ago. 2019.

MILITARIZACIÓN: Amilcar Pop denuncia militarización en Huehuetenango. Canal Antigua, Guatemala, 2014. Disponible en: <https://canalantigua. tv/militarizacion/>. Acceso en: 17 abr. 2016.

OLIVEIRA, A. C. M. The crude face of mining and energy production: narratives of violence and paths of resistance in the Northern Huehuetenango, Guatemala. 2016. 78f. Dissertação (Mestrado Acadêmico em Estudos da Globalização) - Universidade de Freiburg e FlacsoArgentina, Freiburg, 2016.

ORGANIZACIONES denuncian desplazamiento forzado de la comunidade de Laguna Larga, de Guatemala. Radio Mundo Real, [on line], 12 jun. 2017. Disponible em: <http://radiomundoreal.fm/9827-areas-protegidascomo-excusa?lang=es $>$. Acceso en: 04 ago. 2019.

PÉREZ PENA, M. Responsabilizan a Hidralia da violencia contra as mulleres en Barillas (Guatemala). Praza, Galicia, 30 ago. 2012. Disponible en: <https://praza.gal/movementos-sociais/responsabilizan-a-hidraliada-violencia-contra-as-mulleres-en-barillas-guatemala>. Acceso en: 17 abr. 2016.

PRESIDENTE garantiza al CACIF seguridad en hidroeléctrica de San Mateo Ixtatán, Huehuetenado. Reportaje: Henry Pocasangre. Ciudad de Guatemala: Diario de Centro América, 2014. 1 video (1 min, 7 seg), son., color. Idioma: español. Subtítulos: español. Disponible en: <https://www. youtube.com/watch?V=Ji_VUKqxy4Q>. Acceso en: 04 ago. 2019.

SANDT, J. Mining Conflicts and Indigenous Peoples in Guatemala. Haia: Cordaid, 2009. 
TZUL, G. T. San Juan Sacatepéquez: una lucha abierta en la Guatemala del despojo - las doce comunidades kaqchikeles contra la Cementera San Gabriel. In: COMPOSTO, C.; NAVARRO, M. L. (comp.). Territorios en disputa: despojo capitalista, luchas en defensa de los bienes comunes naturales y alternativas emancipatorias para América Latina. Ciudad de México, D. F.: Bajo Tierra Ediciones, 2014. p.168 - 179.

UDEFEGUA - Unidad de Protección a Defensoras y Defensores de Derechos Humanos. Las voces del río: relatos de la persecución política en Barillas. Ciudad de Guatemala: Udefegua, 2014.

Más pequeños que David: la lucha de los defensores y defensoras de derechos humanos en Guatemala. Ciudad de Guatemala: Udefegua, 2015.

ZIBECHI, R. El estado de excepción como paradigma político del extractivismo. In: COMPOSTO, C.; NAVARRO, M. L. (comp.). Territorios en disputa: despojo capitalista, luchas en defensa de los bienes comunes naturales y alternativas emancipatorias para América Latina. Ciudad de México, D. F.: Bajo Tierra Ediciones, 2014. p. 76 - 88. 